\title{
Stasis in the smaller owls from Rancho La Brea during the last glacial-interglacial climate change
}

\author{
Meena Madan, Donald R. Prothero, and Valerie J.P. Syverson
}

\begin{abstract}
Conventional evolutionary biology highlights examples like the Galápagos finches, which show rapid responses to climatic change. Previous studies of many common birds of La Brea, including Teratornis merriami, La Brea Condors (Gymnogyps amplus), Golden Eagles (Aquila chrysaetos), Bald Eagles (Haliaeetus leucocephalus), Californian Turkeys (Meleagris californica), Caracaras (Caracara plancus prelutosus), and Black Vultures (Coragyps occidentalis), as well as the two larger owls, the Great Horned Owl (Bubo virginianus) and the Barn Owl (Tyto alba), showed complete stasis in size and shape through the last glacial-interglacial cycle. Are the smaller birds, especially the small owls, as unresponsive to climate change as the larger birds, or are they more like the Galápagos finches? We measured the large samples of the crow-sized Long-Eared Owl (Asio otus) and the robin-sized Burrowing Owl (Athene cunicularia) from the collections of the La Brea Tar Pits Museum to determine if they showed size or shape changes in response to the climate changes of the last 35,000 years. Even though living Burrowing Owls exhibit a weak Bergmann's rule effect, with larger subspecies in colder climates, neither species of small owls from Rancho La Brea showed statistically significant changes in size or robustness even during the peak glacial interval at 20,000-18,000 years ago, when the climate at Rancho La Brea was dominated by coniferous forests and snowy winters. Apparently, most birds do not respond to long-term changes in climate in a simple fashion, but are ecologically flexible and live in a wide range of habitats and climates without change in size or limb robustness.
\end{abstract}

Meena Madan. School of Earth Sciences, University of Bristol, Bristol, BS8 1TQ, UK; mm13970@my.bristol.ac.uk;

Donald R. Prothero. Natural History Museum of Los Angeles County, 900 Exposition Blvd., Los Angeles, CA 90007; donaldprothero@att.net (corresponding author)

Valerie J.P. Syverson. Dept. Geosciences, Univ. Wisconsin, 1215 W. Dayton St., Madison, WI 53706; vsyverson@gmail.com

\footnotetext{
Madan, Meena, Prothero, Donald R., and Syverson, Valerie J.P. 2019. Stasis in the smaller owls from Rancho La Brea during the last glacial-interglacial climate change. Palaeontologia Electronica 22.3.70 1-12. https://doi.org/10.26879/960

palaeo-electronica.org/content/2019/2796-stasis-in-pleistocene-owls

Copyright: November 2019 Society of Vertebrate Paleontology.

This is an open access article distributed under the terms of the Creative Commons Attribution License, which permits unrestricted use, distribution, and reproduction in any medium, provided the original author and source are credited.

creativecommons.org/licenses/by/4.0/creativecommons.org/licenses/by-nc-sa/4.0/
} 
Madan, Prothero, \& Syverson: Stasis in Pleistocene OWls

Keywords: Pleistocene; birds; evolution; punctuated equilibria; climate change; owls

Submission: 14 January 2019. Acceptance: 9 October 2019.

\section{INTRODUCTION}

Conventional evolutionary biology has long featured examples of adaptive responses to climatic change, especially in birds such as the Galápagos finches (Weiner, 1995; Grant and Weiner, 1999; Grant and Grant, 2007). There are numerous other demonstrated instances of microevolutionary change in modern birds, such as Siberian Warblers (Locustella thoracica), English Sparrows (Passer domesticus), Cuckoos (Cuculus canorus), Cowbirds (Molothrus ater), Red-Winged Blackbirds (Agelaius phoeniceus), and many others (Weiner, 1995). These studies all suggest that body size and robustness in birds are highly responsive to environmental and climatic changes.

But for 47 years now, paleontologists have documented the prevalence of morphological stasis among fossil populations over long time intervals (Eldredge and Gould, 1972; Eldredge, 1999; Gould, 2002). From this perspective, it seems that the short-term examples of small-scale change may not be very important to large-scale macroevolution. Most fossil metazoans show evolutionary stasis over timescales of millions of years (Jackson and Cheetham, 1999; Jablonski, 2000; Gould, 2002; Jablonski, 2008; Geary, 2009; Hallam, 2009; Princehouse, 2009; Sepkoski and Ruse, 2009; Hunt et al., 2015). There is abundant evidence of stasis during periods of climatic change and stress (e.g., Coope, 1979; Davis, 1983; Bennett, 1990; Prothero and Heaton, 1996; Prothero, 1999; Prothero et al., 2012), which should be intervals of morphological change according to conventional evolutionary biology.

The Rancho La Brea (RLB) tar pits are a perfect place to test the hypothesis of short-term change in response to climate on timescales of thousands of years. The tar pits produce a huge sample of fossil birds with over 85,000 individual bones representing at least 133 species, including 19 extinct species (Howard, 1962). Asphalt is particularly well suited to trapping and preserving delicate bird bones, so there are large samples of many bones from a variety of species and time intervals (Akersten et al., 1983; Stock and Harris, 1992; Friscia et al., 2008). Many of the pits have also been radiocarbon dated (Marcus and Berger, 1984; O'Keefe et al., 2009), so we know the tem- poral sequence of most of the pits and their correspondence to Late Pleistocene climatic cycles.

The RLB tar pits also preserve the climatic record in southern California at the time they formed, based upon data from snails, pollen, plant macrofossils, and stable oxygen isotopes (Warter, 1976; Coltrain et al., 2004; Ward et al., 2005). The best record of this time interval comes from deepsea cores drilled just offshore in the California continental shelf. Based on pollen grains analyzed by Heusser (1998), there was a change from oak and chaparral vegetation about 59 ka to pine-junipercypress woodlands at $24 \mathrm{ka}$, then to a closed-cone juniper-ponderosa forest with abundant winter snow during the last glacial maximum (24-14 ka). During the glacial-interglacial transition from 14 to $10 \mathrm{ka}$, the landscape returned to dominant oakchaparral and coastal sagebrush with pulses of alder. In the past 10,000 years, the region has been vegetated by the modern assemblage of oakchaparral-herbaceous vegetation. According to stable oxygen and carbon isotopic analysis (Coltrain et al., 2004), there was increased seasonal aridity during the last interglacial and previous glacial.

So how did climatic and vegetational change affect the birds at RLB? We might expect to see changes consistent with Bergmann's rule of larger body size in colder climates at the times when Rancho La Brea was at its coldest and snowiest about 20-18 ka ago during the last glacial maximum. The most common bird at RLB, the Golden Eagle (Aquila chrysaetos), shows considerable clinal variation today, with larger-bodied subspecies in the high latitudes in both Siberia and North America (Brown, 1968; Johnsgard, 1990). Yet Molina and Prothero (2011) analyzed the large RLB sample of Golden Eagles and found no indication of larger body sizes during the peak glacial interval at 20-18 ka years ago. Syverson and Prothero (2010) found no size differences over the same period in the third most common bird, the extinct California Condor Gymnogyps amplus. Fragomeni and Prothero (2011) found no significant size or robustness changes in the second most common bird, the extinct Californian Turkey (Meleagris californica), nor in the La Brea Caracara (Caracara plancus prelutosus), nor in the Bald Eagle (Haliaeetus leucocephalus). Gillespy et al. 
(2016) found no size or shape changes in the huge extinct condor-like Teratornis merriami. Long et al. (2016) documented complete size and shape stasis in the Black Vultures (Coragyps occidentalis). Madan et al. (2015) found stasis in the Great Horned Owls (Bubo virginianus), and Madan et al. (2016) documented the same in the Barn Owls (Tyto alba). These are the most common birds in the RLB collections, and all of them exhibit morphological stasis for the later Pleistocene sequence documented at the RLB.

However, these are all relatively large birds, most of which live in large ranges and are able to adapt to a wide variety of habitats. Smaller birds, which tend to have limited geographic ranges and narrower habitat preferences, might be more comparable to the Galápagos finches in their evolutionary response to rapid climate change. For this study, we examined the two common small owls in the RLB collections. One is the crow-sized LongEared Owl (Asio otus), which does not have a strong Bergmann's rule effect in modern populations because it migrates from cold climates in the winter. The other is the robin-sized Burrowing Owl (Athene cunicularia), which has numerous named subspecies, of which the tropical ones are slightly smaller than the ones from colder climates (Duncan, 2003; König and Weick, 2008).

\section{METHODS}

We studied the large sample of Long-Eared Owls and Burrowing Owls in the RLB collections. According to Howard (1962, table 1), the minimum numbers of individuals in the collection are 177 Long-Eared Owls and 228 Burrowing Owls. They have been found in almost every pit, including the oldest pit, Pit 77 (35 ka).
We measured the tarsometatarsus (TMT), which is by far the most robust element in the bird skeleton and is much less likely to be broken or deformed. Based on a more extensive set of measurements in the La Brea condor Gymnogyps amplus (Syverson and Prothero, 2010), which demonstrated no differences between the trends shown in TMT measurements and those of the other parts of the skeleton, we assume that the TMT is a good proxy for within-species body size variation, and it has been widely used by ornithologists and paleo-ornithologists for that purpose. Only complete, undeformed adult TMTs were measured in order to avoid artifacts resulting from breakage or ontogeny.

We searched the museum's Excel database for all RLB birds by the pit number first in order to avoid measuring specimens from pits like Pit 16 , which has problematic, widely scattered radiocarbon ages (Marcus and Berger, 1984; O'Keefe et al., 2009), and so could not be used in our study. For unknown reasons, Pit 16 produces a high percentage of the bird bones from RLB (Howard, 1962), but the dating is too poor to be used for time-series studies like this one. We measured all adult TMT specimens from the pits with well-constrained ages. We also measured TMTs of modern Burrowing Owls from the American Museum of Natural History (AMNH) in New York City, and both Burrowing Owls and Long-Eared Owls from the Museum of Vertebrate Zoology at the University of California (UCMVZ), Berkeley.

We measured a total of 168 Asio otus and 92 Athene cunicularia TMTs with digital metric calipers. Three dimensions were measured (Figure 1): maximum shaft length between the longest proximal-distal ends of the TMT; midshaft anteroposte-

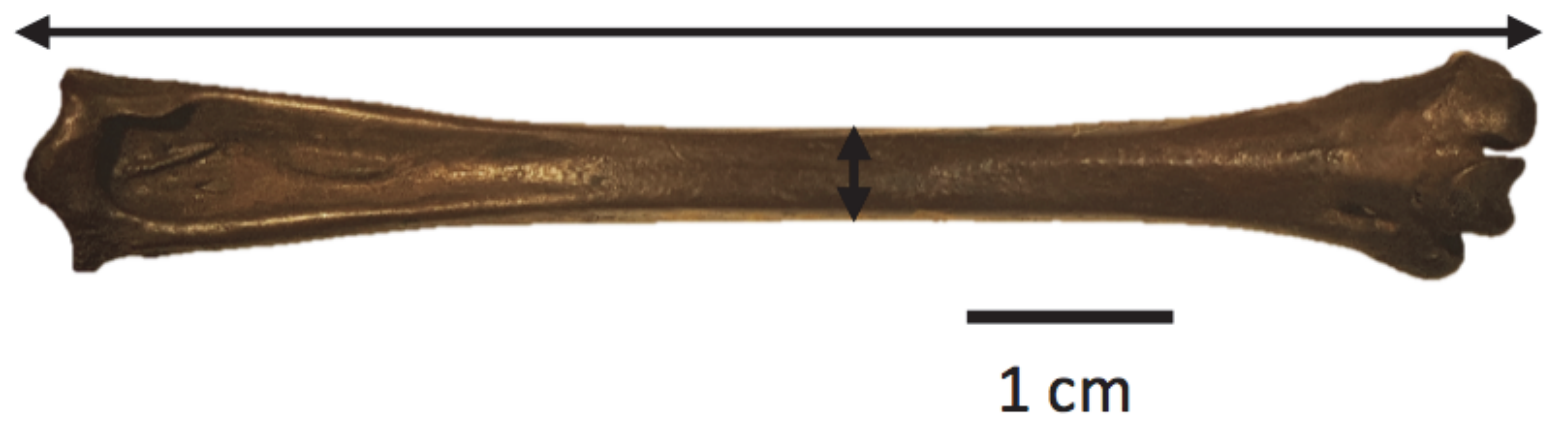

FIGURE 1. Image of a Long-Eared OwI TMT, showing the measurement landmarks. Abbreviations: ML, maximum shaft length between the longest proximal-distal ends of the TMT; MW, midshaft transverse width of the TMT; TMT, tarsometatarsus. 
madan, Prothero, \& Syverson: Stasis in Pleistocene OWLS

TABLE 1. Basic statistics of La Brea TMTs of Athene cunicularia. SD: Standard Deviation; CV: Coefficient of Variation; $\mathrm{N}$ : sample size; TMT: tarsometatarsus.

\begin{tabular}{lccccc} 
Character & $\begin{array}{c}\text { Age } \\
\text { (ka) }\end{array}$ & $\mathbf{N}$ & $\begin{array}{c}\text { Mean } \\
(\mathbf{m m})\end{array}$ & $\begin{array}{c}\text { SD } \\
(\mathbf{m m})\end{array}$ & CV \\
Length & 29 & 12 & 48.60 & 1.41 & 2.90 \\
& 18 & 26 & 47.11 & 1.58 & 3.35 \\
Midshaft transverse width & 14 & 3 & 49.27 & 2.25 & 4.57 \\
& 9 & 33 & 48.09 & 1.78 & 3.71 \\
& 0 & 17 & 46.64 & 3.58 & 7.68 \\
& 29 & 12 & 2.85 & 0.17 & 6.08 \\
Midshaft depth (antero-posterior) & 18 & 26 & 2.75 & 0.25 & 9.23 \\
& 14 & 3 & 2.60 & 0.10 & 3.85 \\
& 9 & 33 & 2.77 & 0.21 & 7.49 \\
& 0 & 17 & 2.85 & 0.39 & 13.83 \\
& 18 & 12 & 2.71 & 0.22 & 8.10 \\
& 14 & 3 & 2.41 & 0.28 & 11.51 \\
& 9 & 33 & 2.38 & 0.27 & 11.30 \\
& 0 & 17 & 2.84 & 0.51 & 18.07 \\
\hline
\end{tabular}

TABLE 2. Basic statistics of La Brea TMTs of Asio otus. SD: Standard Deviation; CV: Coefficient of Variation; N: sample size; TMT: tarsometatarsus.

\begin{tabular}{|c|c|c|c|c|c|}
\hline Character & $\begin{array}{l}\text { Age } \\
\text { (ka) }\end{array}$ & $\mathbf{N}$ & $\begin{array}{l}\text { Mean } \\
(\mathrm{mm})\end{array}$ & $\begin{array}{c}\text { SD } \\
(\mathrm{mm})\end{array}$ & CV \\
\hline \multirow[t]{8}{*}{ Length } & 29 & 23 & 45.26 & 1.48 & 3.27 \\
\hline & 21 & 1 & 42.40 & NA & NA \\
\hline & 18 & 47 & 44.18 & 1.65 & 3.74 \\
\hline & 16 & 1 & 43.20 & NA & NA \\
\hline & 14 & 11 & 44.45 & 1.34 & 3.02 \\
\hline & 11 & 3 & 45.13 & 1.44 & 3.18 \\
\hline & 9 & 74 & 44.40 & 1.76 & 3.97 \\
\hline & 0 & 8 & 44.29 & 1.70 & 3.84 \\
\hline \multirow[t]{8}{*}{ Midshaft transverse width } & 29 & 23 & 4.71 & 0.37 & 7.92 \\
\hline & 21 & 1 & 5.00 & NA & NA \\
\hline & 18 & 47 & 4.54 & 0.29 & 6.49 \\
\hline & 16 & 1 & 5.20 & NA & NA \\
\hline & 14 & 11 & 4.60 & 0.33 & 7.14 \\
\hline & 11 & 3 & 5.00 & 0.10 & 2.00 \\
\hline & 9 & 74 & 4.60 & 0.24 & 5.26 \\
\hline & 0 & 8 & 4.51 & 0.34 & 7.63 \\
\hline \multirow[t]{8}{*}{ Midshaft depth (antero-posterior) } & 29 & 23 & 3.36 & 0.30 & 9.06 \\
\hline & 21 & 1 & 3.00 & NA & NA \\
\hline & 18 & 47 & 3.29 & 0.33 & 10.00 \\
\hline & 16 & 1 & 3.60 & NA & NA \\
\hline & 14 & 11 & 3.23 & 0.21 & 6.36 \\
\hline & 11 & 3 & 3.37 & 0.21 & 6.18 \\
\hline & 9 & 74 & 3.23 & 0.27 & 8.32 \\
\hline & 0 & 8 & 3.46 & 0.13 & 3.76 \\
\hline
\end{tabular}


TABLE 3. Mann-Whitney $U$ tests for each dimension of TMTs for Athene cunicularia, comparing measurements from each time interval to the rest of the pooled samples; jackknife method was used instead of straight pooled variation due to highly uneven sample sizes. Bold face indicates results that are significantly different at $p<0.05$ with Bonferroni correction applied. The significant differences given by this test are consistent with the significance levels reported by the Kruskal-Wallis test $(\mathrm{df}=4)$. Corrected significance level: $p<0.01$. Depth and robustness measurements were significantly different from pooled samples for the $9 \mathrm{ka}$ and modern samples.

\begin{tabular}{ccccccccc}
\hline $\begin{array}{c}\text { Age } \\
\text { (ka) }\end{array}$ & $\mathbf{U}$ & $\mathbf{~ L e n g t h ~}$ & $\mathbf{~}$ & $\mathbf{~ W i d t h ~}$ & \multicolumn{2}{c}{ Depth } & \multicolumn{2}{c}{ Robustness } \\
\hline 29 & 624.5 & 0.078 & 597.5 & 0.145 & 692 & 0.010 & 639.5 & 0.053 \\
18 & 630 & 0.059 & 823.5 & 0.852 & 652 & 0.089 & 733 & 0.327 \\
14 & 187.5 & 0.221 & 59 & 0.103 & 152 & 0.663 & 96 & 0.430 \\
9 & 1090.5 & 0.272 & 905.5 & 0.670 & $\mathbf{6 2 6}$ & $\mathbf{0 . 0 0 6}$ & $\mathbf{5 9 6 . 5}$ & $\mathbf{0 . 0 0 3}$ \\
0 & 504.5 & 0.207 & 651.5 & 0.821 & $\mathbf{9 1 5}$ & $\mathbf{0 . 0 0 4}$ & $\mathbf{9 7 2}$ & $\mathbf{0 . 0 0 1}$ \\
\hline
\end{tabular}

TABLE 4. Mann-Whitney $U$ tests for each dimension of TMTs for Asio otus, comparing measurements from each time interval to the rest of the pooled samples; jackknife method was used instead of straight pooled variation due to highly uneven sample sizes. Corrected significance level: $p<0.00625$. No differences were significant by either test.

\begin{tabular}{ccccccccc}
\hline $\begin{array}{c}\text { Age } \\
(\mathbf{k a})\end{array}$ & $\mathbf{U}$ & $\mathbf{p}$ & $\mathbf{U}$ & $\mathbf{p}$ & $\mathbf{U}$ & $\mathbf{p}$ & $\mathbf{U}$ & $\mathbf{p}$ \\
\hline 29 & 2202 & 0.014 & 2029.5 & 0.093 & 2065 & 0.065 & 2018.5 & 0.106 \\
21 & 18.5 & 0.183 & 152.5 & 0.155 & 27 & 0.244 & 105 & 0.665 \\
18 & 2456 & 0.171 & 2293.5 & 0.051 & 2919 & 0.789 & 2759 & 0.767 \\
16 & 41.5 & 0.392 & 163 & 0.101 & 151 & 0.163 & 164 & 0.099 \\
14 & 875 & 0.944 & 819.5 & 0.779 & 736 & 0.411 & 776.5 & 0.579 \\
11 & 323.5 & 0.366 & 450.5 & 0.015 & 293 & 0.587 & 382 & 0.109 \\
9 & 3384 & 0.765 & 3456 & 0.945 & 2788 & 0.026 & 2916 & 0.073 \\
0 & 606.5 & 0.806 & 542.5 & 0.467 & 928 & 0.031 & 786 & 0.279 \\
\hline
\end{tabular}

rior thickness of the TMT; and midshaft transverse width of the TMT. These values allowed us to calculate a robustness index, the cross-sectional area (depth $\mathrm{x}$ width) divided by the length, to examine shape as well as size.

Once the pit dates had been added to the spreadsheet, we performed basic statistical analysis using Excel for the group of specimens from each well-dated pit. We then tested the samples for normality using the Shapiro-Wilk method. Since none of the pit samples were normally distributed, we used the nonparametric Kruskal-Wallis test to determine whether any sample was significantly different from the pooled mean of all other measurements. The different pit samples were then compared to determine which ones were different from the pooled sample mean minus that group by the Mann-Whitney $U$ test. The time series of each measurement was also fit to evolutionary models (directional random walk, undirected random walk, stasis, and strict stasis) in $\mathrm{R}$ using the paleoTS package (Hunt, 2014).

\section{RESULTS}

The basic statistics of the two different owl TMT samples are shown in Tables 1 and 2. The results from the comparisons are reported in Tables 3 and 4, and shown in Figures 2 to 5 . No measurement on any sample was significantly differently distributed from the remaining specimens in the Long-Eared Owl Asio otus, although the width measurement for the 11 ka group skirted significance. In the Burrowing Owl Athene cunicularia, the $9 \mathrm{ka}$ and 0 ka samples had a significantly different distribution in depth and robustness, but we find no evidence of larger body size or increased robustness in the samples from around the last glacial maximum at 20-18 ka.

Evaluating models for the time series (Tables 5, 6; Figures 6, 7) confirms the lack of any overall directional change over the time period being analyzed. The best evolutionary model for most of the time series is stasis (i.e., no change in mean value), with the exception of the derived robustness measure in Athene. Indeed, for five of the 


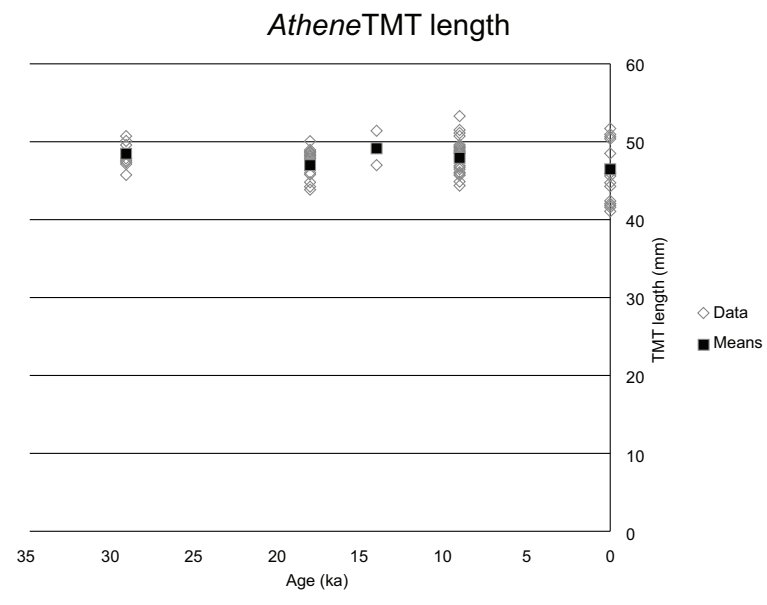

FIGURE 2. Plot of the lengths of La Brea Athene cunicularia TMTs through time. Open diamonds: individual specimens; solid squares: mean for each pit.

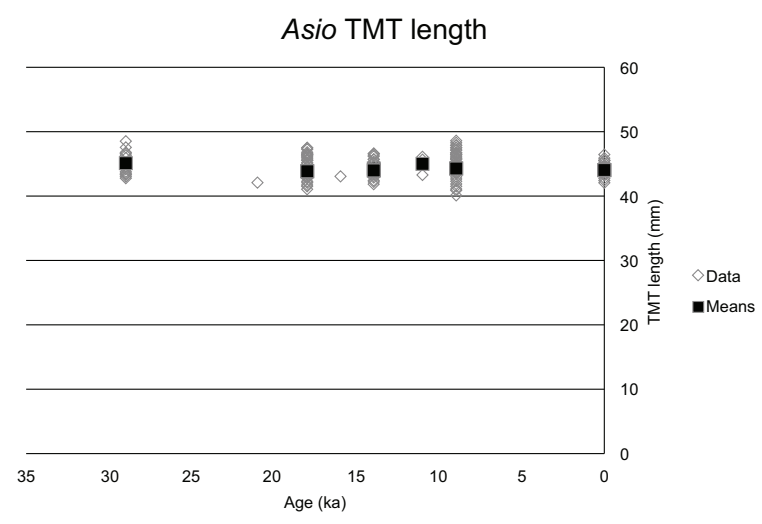

FIGURE 3. Plot of the lengths of La Brea Asio otus TMTs through time. Open diamonds: individual specimens; solid squares: mean for each pit.

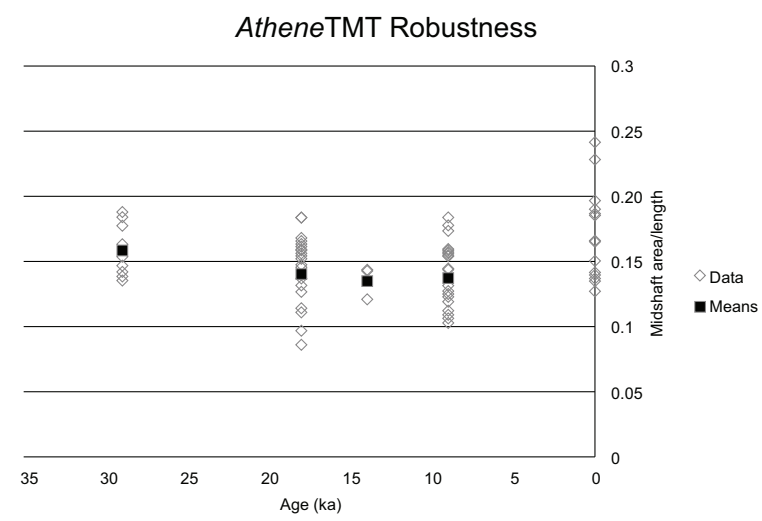

FIGURE 4. Plot of the robustness (midshaft cross-sectional area divided by length) of Athene cunicularia TMTs through time. Open diamonds: individual specimens; solid squares: mean for each pit.

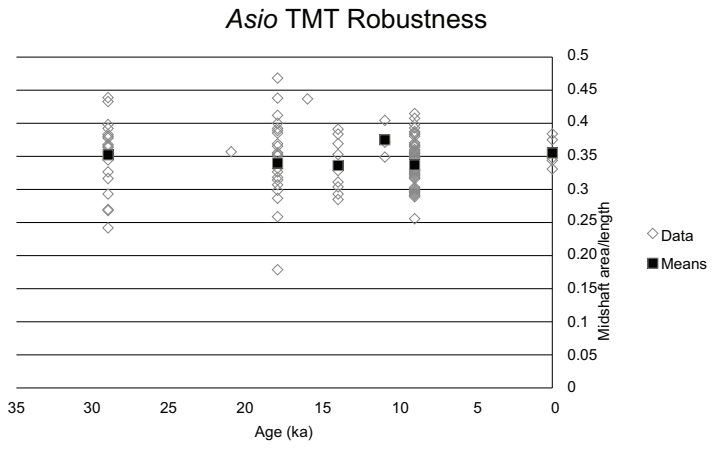

FIGURE 5. Plot of the robustness (midshaft cross-sectional area divided by length) of Asio otus TMTs through time. Open diamonds: individual specimens; solid squares: mean for each pit.

TABLE 5. Time-series analysis, given in Akaike weights, for Athene cunicularia. GRW: general random walk; URW: unidirectional random walk; for "strict stasis" definition, see Hunt et al. (2015). The favored model for each time series is shown in bold face. Strict stasis was preferred for length and width measurements. Depth measurements fit best as ordinary stasis (i.e., true mean not constrained) due to the larger measurements in the $0 \mathrm{ka}$ group. Robustness, derived from the combination of the three measurements, favored an unbiased random walk model.

\begin{tabular}{lcccc}
\hline & GRW & URW & Stasis & Strict stasis \\
\hline Length & 0 & 0.076 & 0.146 & $\mathbf{0 . 7 7 8}$ \\
Width & 0 & 0.055 & 0.085 & $\mathbf{0 . 8 6}$ \\
Depth & 0 & 0.422 & $\mathbf{0 . 5 6 1}$ & 0.017 \\
Robustness & 0 & $\mathbf{0 . 6 1 3}$ & 0.353 & 0.035 \\
\hline
\end{tabular}

TABLE 6. Time-series analysis, given in Akaike weights, for Asio otus. GRW: general random walk; URW: unidirectional random walk; for "strict stasis" definition, see Hunt et al. (2015). The favored model for each time series is shown in bold face. All time series best fit a strict stasis model except width, which favored ordinary stasis due to the large difference in the 12 ka sample.

\begin{tabular}{lcccc}
\hline & GRW & URW & Stasis & $\begin{array}{c}\text { Strict } \\
\text { stasis }\end{array}$ \\
\hline Length & 0.003 & 0.089 & 0.102 & $\mathbf{0 . 8 0 7}$ \\
Width & 0.001 & 0.08 & $\mathbf{0 . 9 1 9}$ & 0 \\
Depth & 0.003 & 0.35 & 0.56 & $\mathbf{0 . 0 8 8}$ \\
Robustness & 0 & 0.068 & 0.107 & $\mathbf{0 . 8 2 5}$ \\
\hline
\end{tabular}




\section{Asio (with $\mathrm{AMNH}$ specimens)}
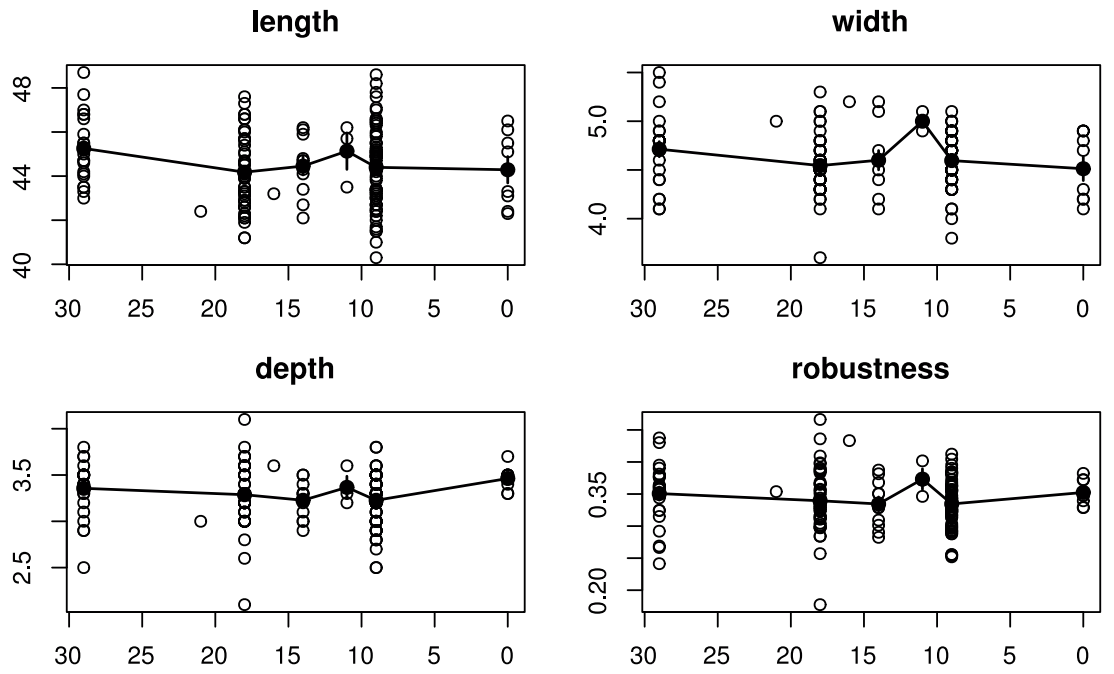

FIGURE 6. Time-series analysis of length $(\mathrm{mm})$, width $(\mathrm{mm})$, depth $(\mathrm{mm})$, and robustness of tarsometarsi of Asio otus through the last $29 \mathrm{ka}$ at RLB. As is apparent from the statistical analysis (Table 6), they exhibit either a unidirectional random walk or complete stasis.

eight time series modeled, the best model is strict stasis, which is defined in the paleoTS implementation as a stasis model with zero variance around the long-term mean. The exceptions are depth and robustness in Athene and width in Asio. Comparing the summary statistics (Table 1 ) with the evolution- ary model fit results makes it apparent that the $0 \mathrm{ka}$ sample of Athene has unusually short and deep (anteroposteriorly thick) TMTs, which is the likely reason why strict stasis does not model these time series well (but see below). The Asio width result appears to be due entirely to the small $(n=3)$ and

\section{Athene (with AMNH specimens)}

length
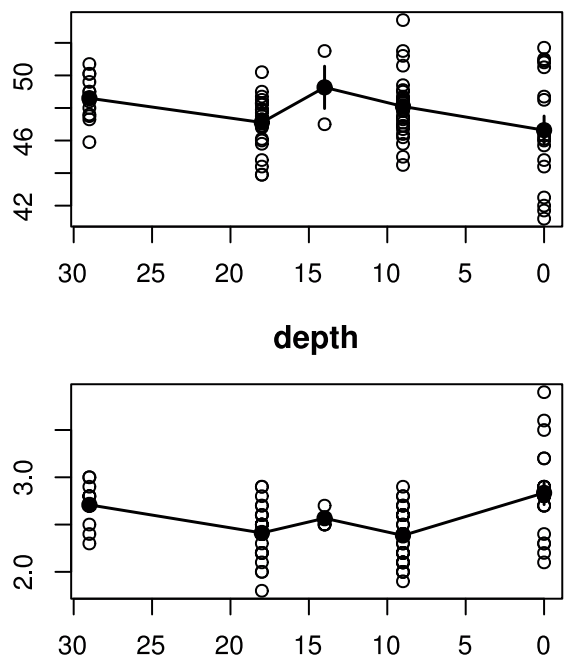

width

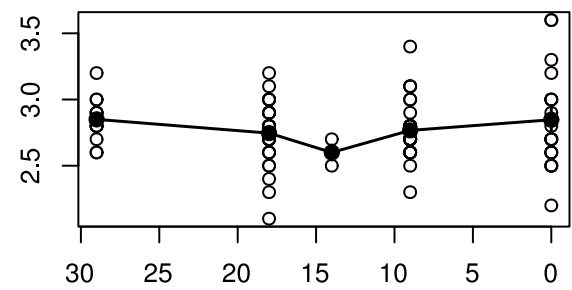

robustness

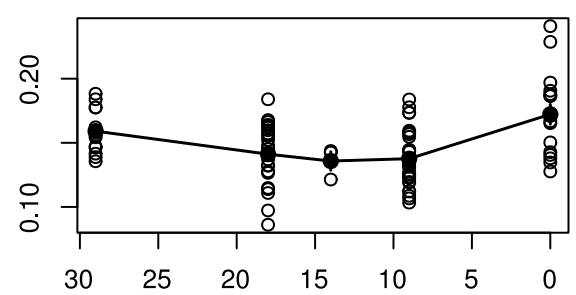

FIGURE 7. Time-series analysis of length $(\mathrm{mm})$, width $(\mathrm{mm})$, depth $(\mathrm{mm})$, and robustness of tarsometarsi of Athene cunicularia through the last $29 \mathrm{ka}$ at RLB. As is apparent from the statistical analysis (Table 5), they exhibit either a unidirectional random walk or complete stasis. 
anomalously wide $11 \mathrm{ka}$ sample. No trend of greater size or robustness occurs around the $18 \mathrm{ka}$ sample at the peak of the glaciation in either species.

In consideration of the fact that the 0 ka sample of Burrowing Owls consisted of samples from two institutions on opposite sides of North America, which could potentially introduce a confounding geographic signal, we also analyzed a reduced data set containing only the UCMVZ and RLB specimens and excluding those from $A M N H$. Although the AMNH and UCMVZ specimens were not significantly different in any dimension (twotailed t-test, significance threshold $p<0.05$ ), their distributions were not identical. The reduced data set displayed some minor differences from the full data set: it had no significant difference in robustness, but the 29 ka sample emerged as significantly larger in the depth dimension. Most of the short and deep TMTs in the 0 ka sample were AMNH specimens. Therefore, the time series model fit results with the reduced data set were similar to those with the full data set, except for the robustness time series, which without the AMNH specimens favored a strict stasis model over a random walk.

\section{DISCUSSION}

There is no evidence of significant size or shape changes in the small owls across the last glacial maximum despite the dramatic changes in climate and vegetation documented in the region over the past 40,000 years, consistent with the previous analyses of all the common larger birds at RLB. As is the case with Golden Eagles (Molina and Prothero, 2011), Bald Eagles and Caracaras (Fragomeni and Prothero, 2011), Great Horned Owls (Madan et al., 2015), and Barn Owls (Madan et al., 2016), modern Burrowing Owl subspecies exhibit clinal variation in size over latitude following Bergmann's rule (Duncan, 2003; König and Weick, 2008). Yet at RLB, even conditions of coniferous forests and frequent snow at low elevations around 20-18 ka did not cause measurable increases in body size in any of these birds. This trend is also consistent with nearly all the larger mammals of RLB, which also show no response in size or shape during the maximum climatic changes of the past 35,000 years (Prothero and Raymond, 2008; DeSantis et al., 2011; Madan et al., 2011; Prothero and Raymond, 2011; Raymond and Prothero, 2011; Prothero et al., 2012). Numerous studies (Barnosky, 1994, 2005) document stasis in body size in nearly every Pleistocene mammal lineage, even though many of these species ranged through several glacial-interglacial cycles. Thus, stasis in body size is a widespread phenomenon in nearly all Pleistocene birds and mammals over the entire span of several glacial-interglacial cycles.

Paleontologists and neontologists have long argued about the significance of stasis despite changes in environment. It is clearly inconsistent with the notion of adaptive sensitivity shown by the Galápagos finches and other recently documented examples of adaptation and microevolution on short time scales (Weiner, 1995). Ideas like stabilizing selection (Estes and Arnold, 2007) are clearly inapplicable and fail to explain this phenomenon, since the environment in this case is changing, not stabilizing (Lieberman and Dudgeon, 1996). Other ideas, such as developmental canalization, have been used to explain this stability, but this model has fallen out of favor in view of the phenotypic plasticity of domesticated animals, such as dogs (Gould, 2002; Eldredge et al., 2005). Bennett $(1990,1997)$ argued that the climate changes of the Pleistocene were too rapid for organisms to respond, but the Pleistocene fossil record spans tens to hundreds of thousands of years. If the Galápagos finches could show change in just a few years, then evolutionary changes could occur in a matter of years or decades. Although it has been suggested that mean phenotype fluctuates on a time scale rapid enough to appear static in the fossil record, most RLB pits have narrow enough time constraints that they should capture changes on this time scale.

However, recent studies using large databases of evolutionary time series indicate that such classic examples of rapid change, rather than constituting true evolutionary shifts in the species' adaptive zone, more likely result from short-term, reversible shifts within the species' existing adaptive zone. Uyeda et al. (2011) looked at data from short time scales of historic data up to million-year time scales. They found that rapid short-term evolution on timescales of decades to centuries are highly constrained ("bounded fluctuations") and do not accumulate change over time or produce major adaptive shifts or new species. Instead, rare bursts of change that accumulate over million-year timescales account for most of the morphological changes and speciation within lineages, strongly confirming the original punctuated equilibria model of Eldredge and Gould (1972). Hunt et al. (2015) similarly found that $38 \%$ of paleontological time series were best fit by a stasis model across a wide range of taxa and temporal resolutions, but espe- 
cially for time series driven by sub-million-year fluctuations in global temperature.

The most widely accepted explanation for long-term stasis is the idea that most organisms that have large geographic ranges are also adapted to a wide spectrum of local environments, so they do not respond to environmental change by means of morphological change (Lieberman et al., 1995; Lieberman and Dudgeon, 1996; Eldredge, 1999; Eldredge et al., 2005). This might be appropriate for large birds that range all over the Americas, but not for smaller birds, some of which live in very small areas. However, both the owl species in this study, including the small and sedentary Burrowing Owl, are just as static in the face of climate change as the larger birds of RLB. Most species of Pleistocene small mammals also remain static in size through changing climate regimes (Barnosky, 2005). Such stasis in small mammal populations is also apparent during late Eocene-Oligocene climate changes (Prothero and Heaton, 1996). Whatever the mechanism may be that maintains stasis in body size over this range of timescales, it does not appear to be contingent on a species' size or its consequent range of environmental tolerance.

\section{CONCLUSIONS}

Statistical analysis of size and shape variables of the Long-Eared Owls and Burrowing Owls of RLB demonstrates almost no significant size or robustness change in response to the dramatic cooling and vegetational change of the peak glacial period 20,000 years ago or the subsequent warming. This is consistent with previous studies showing stasis in Golden Eagles, Bald Eagles, Condors, Turkeys, Caracaras, Teratorns, Black Vultures, Great Horned Owls, and Barn Owls, despite their strong tendency in many of these species to follow Bergmann's rule (Syverson and Prothero, 2010; Fragomeni and Prothero, 2011; Molina and Prothero, 2011; Madan et al., 2015; Gillespy et al., 2016; Madan et al., 2016). This agrees with the evidence that all RLB mammals and birds with sufficient sample sizes also show complete stasis across the major climatic shifts in and out of the last glacial maximum. This phenomenon seems to be explained by recent model-fitting results, which confirm that short-term morphological changes are not cumulative, but concentrated in rapid bursts of evolution and speciation observable over long million-year time scales, followed by long-term stasis (Uyeda et al., 2011). Although the stasis exhibited by larger mammals and birds might be explained by wide geographic ranges and environmental flexibility, this model does not yet explain why environmentally restricted, nonmigratory mammals and birds with small body sizes and home ranges also demonstrate stasis.

\section{ACKNOWLEDGMENTS}

We thank A. Farrell, J. Harris, and especially K. Campbell, Jr., for allowing access to the La Brea Tar Pits Museum collection of birds. We thank C. Cicero of the University of California Museum of Vertebrate Zoology, and P. Capainolo, L. Garetano, and J. Cracraft of the American Museum of Natural History Department of Ornithology for allowing us to measure modern birds in their collections. We thank two anonymous reviewers for their helpful comments on the manuscript. DRP is grateful to the late L. Marcus for teaching him biometrics and for introducing him to the wonders of Rancho La Brea.

\section{REFERENCES}

Akersten, W.A., Shaw, C.A., and Jefferson, G.T. 1983. Rancho La Brea: status and future. Paleobiology, 9:211-217. https://doi.org/10.1017/S0094837300007648

Barnosky, A.D. 1994. Defining climate's role in ecosystem evolution: clues from late Quaternary mammals. Historical Biology, 18:173-190. https://doi.org/10.1080/10292389409380476

Barnosky, A.D. 2005. Effects of Quaternary climatic change on speciation of mammals. Journal of Mammalian Evolution, 12:247-264. https://doi.org/10.1007/s10914-005-4858-8

Bennett, K.D. 1990. Milankovitch cycles and their effects on species in ecological and evolutionary time. Paleobiology, 16:11-21. https://doi.org/10.1017/S0094837300009684

Bennett, K.D. 1997. Evolution and Ecology: The Pace of Life. Cambridge University Press, Cambridge. https://doi.org/10.1017/s0025315400071915

Brown, L. 1968. Eagles, Hawks, and Falcons of the World. McGraw-Hill, New York. 
Coltrain, J.B., Harris, J.M., Cerling, T.E., Ehleringer, J.R., Dearing, M., Ward, J., and Allen, J., 2004. Rancho La Brea stable isotope biogeochemistry and its implications for the palaeoecology of the late Pleistocene, coastal southern California. Palaeogeography, Palaeoclimatology, Palaeoecology, 205:199-219. https://doi.org/10.1016/ j.palaeo.2003.12.008

Coope, G.R. 1979. Late Cenozoic fossil Coleoptera: evolution, biogeography, and ecology. Annual Reviews of Ecology and Systematics, 10:247-267. https://doi.org/10.1146/ annurev.es.10.110179.001335

Davis, M. 1983. Quaternary history of deciduous forests of eastern North America and Europe. Annals of the Missouri Botanical Garden, 20:550-563. https://doi.org/10.2307/2992086

DeSantis, S.N., Prothero, D.R., and Gage, G.L. 2011. Size and shape stasis in late Pleistocene horses and camels from Rancho La Brea during the last glacial-interglacial cycle. New Mexico Museum of Natural History Bulletin, 53:505-510.

Duncan, J.R. 2003. Owls of the World: Their Lives, Behavior, and Survival. Firefly Books, New York.

Eldredge, N. 1999. The Pattern of Evolution. W. H. Freeman, New York.

Eldredge, N. and Gould, S.J. 1972. Punctuated equilibria: an alternative to phyletic gradualism, p. 82-115. In Schopf, T.J.M. (ed.), Models in Paleobiology. Freeman, Cooper and Company, San Francisco.

Eldredge, N., Thompson, J.N., Brakefield, P.M., Gavrilets, S., Jablonski, D., Jackson, J.B.C., Lenski, R.E., Lieberman, B.S., McPeek, M.A., and Miller III, W. 2005. The dynamics of evolutionary stasis. Paleobiology, 31:133-145. https://doi.org/10.1666/00948373(2005)031[0133:tdoes]2.0.co;2

Estes, S. and Arnold, S.J. 2007. Resolving the paradox of stasis: models with stabilizing selection explain evolutionary divergence on all timescales. American Naturalist, 169:227244. https://doi.org/10.1086/510633

Fragomeni, A. and Prothero, D.R. 2011. Stasis in late Quaternary birds from the La Brea tar pits during the last glacial-interglacial cycle. New Mexico Museum of Natural History Bulletin, 53:511-516.

Friscia, A.R., Van Valkenburgh, B., Spencer, L., and Harris, J.M. 2008. Chronology and spatial distribution of large mammal bones in Pit 91, Rancho La Brea. Palaios, 23:35-42. https:// doi.org/10.2110/palo.2005.p05-143r

Geary, D.H. 2009. The legacy of punctuated equilibria, p. 127-147. In Allmon, W.D., Kelley, P.H., and Ross, R.M. (eds.), Stephen Jay Gould: Reflections on His View of Life. Oxford University Press, Oxford.

Gillespy, P.D., Prothero, D.R., and Syverson, V.G.P. 2016. Stasis in teratorns from the La Brea tar pits during the last glacial-interglacial cycle. New Mexico Museum of Natural History Bulletin, 74:67-71.

Gould, S.J. 2002. The Structure of Evolutionary Theory. Harvard University Press, Cambridge, Massachusetts.

Grant, P.R. and Weiner, J. 1999. The Ecology and Evolution of Darwin's Finches. Princeton University Press, Princeton.

Grant, P.R. and Grant, B.R. 2007. How and Why Species Multiply: The Radiation of Darwin's Finches. Princeton University Press, Princeton.

Hallam, A. 2009. The problem of punctuational speciation and trends in the fossil record, p. 423432. In Sepkoski, D. and Ruse, M. (eds.), The Paleobiological Revolution. University of Chicago Press, Chicago. https://doi.org/10.7208/chicago/9780226748597.003.0023

Heusser, L. 1998. Direct correlation of millennial-scale changes in western North American vegetation and climate with changes in the California Current system over the past $60 \mathrm{kyr}$. Paleoceanography, 13:252-262. https://doi.org/10.1029/98pa00670

Howard, H. 1962. A comparison of avian assemblages from individual pits at Rancho La Brea, California. Contributions in Science, Natural History Museum of Los Angeles County, 58:124.

Hunt, G. 2014. paleoTS: Modeling evolution in paleontological time-series. Version 0.4-5. Available at https://cran.r-project.org/web/packages/paleoTS

Hunt, G., Hopkins, M.J., and Lidgard, S. 2015. Simple versus complex models of trait evolution. Proceedings of the National Academy of Sciences, 112:4885-4890. https://doi.org/10.1073/ pnas. 1403662111 
Jablonski, D. 2000. Micro- and macroevolution: scale and hierarchy in evolutionary biology and paleobiology. Paleobiology, 26:15-52. https://doi.org/10.1666/00948373(2000)26[15:mamsah]2.0.co;2

Jablonski, D. 2008. Species selection: theory and data. Annual Review of Ecology, Evolution, and Systematics, 39:501-524. https://doi.org/10.1146/annurev.ecolsys.39.110707.173510

Jackson, J.B.C. and Cheetham, A.H. 1999. Tempo and mode of speciation in the sea. Trends in Ecology and Evolution, 14:72-77. https://doi.org/10.1016/s0169-5347(98)01504-3

Johnsgard, P.A. 1990. Hawks, Eagles, and Falcons of North America. Smithsonian Institution Press, Washington, DC.

König, C. and Weick, F. 2008. Owls: A Guide to the Owls of the World (2nd ed.). Yale University Press, New Haven, Connecticut.

Lieberman, B.S., Brett, C.E., and Eldredge, N. 1995. A study of stasis and change in two species lineages from the Middle Devonian of New York State. Paleobiology, 21:15-27. https:// doi.org/10.1017/s0094837300013051

Lieberman, B.S. and Dudgeon, S. 1996. An evaluation of stabilizing selection as a mechanism for stasis. Palaeogeography, Palaeoclimatology, Palaeoecology, 12:229-238. https://doi.org/ 10.1016/s0031-0182(96)00097-1

Long, K.L., Prothero, D.R., and Syverson, V.J.P. 2016. Stasis in Rancho La Brea black vultures (Coragyps occidentalis) over the last glacial-interglacial cycle. New Mexico Museum of Natural History Bulletin, 74:121-125.

Madan, M., Prothero, D.R., and Sutyagina, A., 2011. Did felids from Rancho La Brea change size or shape in the last Pleistocene? New Mexico Museum of Natural History Bulletin, 53:554-563.

Madan, M.A., Prothero, D.R., and Syverson, V.J.P. 2015. Stasis in Great Horned Owls from the La Brea tar pits during the last glacial-interglacial cycle. New Mexico Museum of Natural History Bulletin, 65:221-225.

Madan, M., Prothero, D.R., and Syverson, V.J.P. 2016. Stasis in barn owls from the La Brea tar pits during the last glacial-interglacial cycle. New Mexico Museum of Natural History Bulletin, 74:153-157.

Marcus, L.F. and Berger, R. 1984. The significance of radiocarbon dates for Rancho La Brea, p. 159-188. In Martin, P.S. and Klein, R.G. (eds.), Quaternary Extinctions: A Prehistoric Revolution. University of Chicago Press, Chicago.

Molina, S. and Prothero, D.R. 2011. Stasis in late Quaternary golden eagles from La Brea Tar Pits over the last glacial-interglacial cycle. New Mexico Museum of Natural History Bulletin, 53:564-569.

O'Keefe, F.R., Fet, E.V., and Harris, J.M. 2009. Compilation, calibration, and synthesis of faunal and floral radiocarbon dates, Rancho La Brea, California. Contributions in Science, Natural History Museum of Los Angeles County, 518:1-16.

Princehouse, P. 2009. Punctuated equilibria and speciation: what does it mean to be a Darwinian? p. 149-175. In Sepkoski, D. and Ruse, M. (eds.), The Paleobiological Revolution. University of Chicago Press, Chicago. https://doi.org/10.7208/chicago/ 9780226748597.003.0009

Prothero, D.R. 1999. Does climatic change drive mammalian evolution? GSA Today, 9:1-5.

Prothero, D.R. and Heaton, T.H. 1996. Faunal stability during the early Oligocene climatic crash. Palaeogeography, Palaeoclimatology, Palaeoecology, 127:239-256. https://doi.org/10.1016/ s0031-0182(96)00099-5

Prothero, D.R. and Raymond, K.R. 2008. Variability and sexual size dimorphism in Pleistocene ground sloths (Xenarthra). New Mexico Museum of Natural History and Science Bulletin, 44:331-334.

Prothero, D.R. and Raymond, K.R. 2011. Stasis in late Pleistocene ground sloths (Paramylodon harlani) from Rancho La Brea, California. New Mexico Museum of Natural History Bulletin, 53:624-628.

Prothero, D.R., Syverson, V., Raymond, K.R., Madan, M.A., Fragomeni, A., Molina, S., Sutyagina, A., DeSantis, S., and Gage, G.L. 2012. Stasis in the face of climatic change in late Pleistocene mammals and birds from Rancho La Brea, California. Quaternary Science Reviews, 56:1-10. https://doi.org/10.1016/j.quascirev.2012.08.015

Raymond, K.R. and Prothero, D.R. 2011. Did climate change affect size in late Pleistocene bison? New Mexico Museum of Natural History Bulletin, 53:636-640. 
Sepkoski, D. and Ruse, M. (eds.) 2009. The Paleobiological Revolution. University of Chicago Press, Chicago.

Stock, C. and Harris, J.M. 1992. Rancho La Brea: A record of Pleistocene life in California. Natural History Museum of Los Angeles County, Science Series, 37:1-113.

Syverson, V.J. and Prothero, D.R. 2010. Evolutionary patterns in late Quaternary California condors. PalArch's Journal of Vertebrate Paleontology, 7:1-18.

Uyeda, J.C., Hansen, T.F., Arnold, S.J., and Pienaar, J. 2011. The million-year wait for macroevolutionary bursts. Proceedings of the National Academy of Sciences, 108:1590815913. https://doi.org/10.1073/pnas.1014503108

Ward, J.W., Harris, J.M., Cerling, T.E., Wiedenhoeft, A., Lott, M.J., Dearing, M., Coltrain, J.B., and Ehleringer, J.R. 2005. Carbon starvation in glacial trees recovered from the La Brea tar pits, southern California. Proceedings of the National Academy of Sciences, 102:690-694. https://doi.org/10.1073/pnas.0408315102

Warter, J.K. 1976. Late Pleistocene plant communities_evidence from Rancho La Brea tar pits. Symposium Proceedings on the Plant Communities of Southern California. Native Plant Society Special Publication, 2:32-39.

Weiner, J. 1995. The Beak of the Finch: A Story of Evolution in Our Own Time. Vintage. New York. 